\title{
DePOIMENTO SOBRe VILANOVA ARTIGAS
}

\author{
PEDRO PAULO DE MELO SARAIVA
}

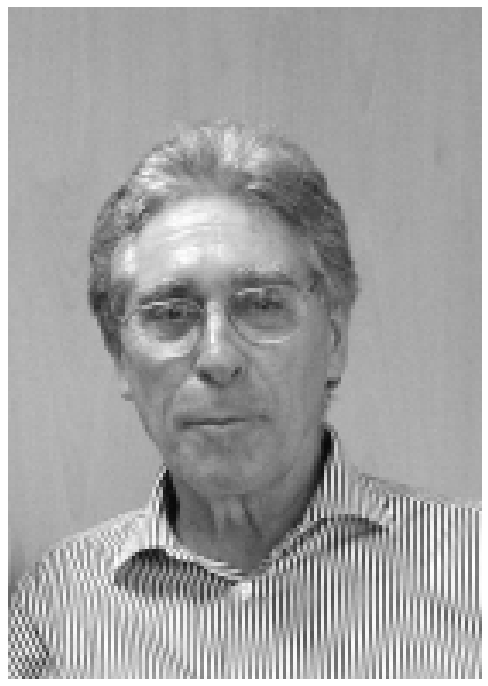

Conheci Artigas, inicialmente, por suas obras. Com efeito, um dos primeiros números da revista Habitat publicou uma série de casas, entre elas a do próprio. A solução "asa de andorinha" como era chamada com núcleo de banheiro, cozinha, lavanderia e caixa d'água - foi muito impactante para jovens como eu, na época ainda na faculdade.

Para mim e tantos outros, Artigas era uma figura meio etérea, taciturna, portando um corte de cabelo paramilitar, gravata borboleta, enfim, uma pessoa meio esquiva e esquisita.

Conheci-o, de fato, no IAB, na gestão de Ícaro de Castro Mello, presidente, e ele vice. Eu fazia parte da diretoria, sem atribuições ou funções específicas. Faziam parte dessa e da diretoria reeleita pessoas como Paesani, Corona, Millan, Luiz Roberto Carvalho Franco, Breno Cirino, entre outros.

Nesse fim dos anos 50 foi justamente no $\mathrm{I} A \mathrm{~B}$, onde nos encontrávamos para almoçar e discutir nossos problemas, que realmente conheci Artigas em sua dimensão maior. O extremo apego aos valores morais, partidarismo exacerbado, e pasmem, alguma candura e grande generosidade. Não esqueço nunca o episódio que envolveu o arquiteto Luis Saia no trato do plano diretor de Goiânia. Na controversa contribuição de Saia para fazer o projeto, Artigas defendeu nosso colega com grande ardor e convicção. Estava esquecendo de lembrar seu famoso artigo sobre o Modulor e Le Corbusier. Na época considerei um pouco radical a postura do mestre. Ninguém é perfeito e Artigas tinha seu calcanhar de Aquiles. Às vezes defendia causas em que talvez nem acreditasse (por dever 
de ofício). Eram as palavras do Partidão, ao qual Artigas jamais traiu ou deixou de defender com entusiasmo esfuziante. A veemência na defesa de suas convicções era sua marca indelével. Sempre dizia: "Não é no plano estético que vamos nos dividir." Era o chamamento permanente que fazia ao acordo que devíamos assumir entre nós, arquitetos, com vista ao desenvolvimento do país. Conhecendo melhor sua obra, mais admiramos sua trajetória. Sua passagem pela América, o prêmio Guggenheim, suas primeiras casas wrightianas e sua adesão a uma arquitetura brasileira sem adjetivos. A perseguição de sua própria linguagem não decorre de um irrefletido sentido de busca de originalidade nem de um frívolo objetivo; é, sim, um mergulho na cultura brasileira de Gregório de Mattos a Mário de Andrade. Esse é um de seus legados.

Revolvendo esse passado quase remoto (50 anos), não posso deixar de lembrar o episódio do concurso do Paulistano, vencido por Paulo Mendes da Rocha. Nós, eu e Paulo, com Alfredo Paesani havíamos vencido o Concurso da Assembléia Legislativa de Santa Catarina. Em seguida, separamo-nos para participar do Concurso do Paulistano. Na época, éramos um pouco irresponsáveis, não no sentido pejorativo, mas no fazer arquitetura. Explico-me - não teorizamos demais, partimos para fazer arquitetura com muito entusiasmo. Pois bem, na FAU Maranhão houve um início de comemoração em torno da suposta vitória de Artigas nesse concurso (do Paulistano). Vazou uma informação que o projeto vencedor era atirantado. O Paesani, amigo de Plínio Croce, membro do júri, prontificou-se a falar com ele, pois o projeto de Paulo M. da Rocha, muito elegante e inventivo também, era atirantado. Lá fomos, Miguel Juliano, Paulo Mendes da Rocha, Paesani e eu para a Barão de Itapetininga, escritório do Plínio e do Aflalo, a fim de forçá-lo a uma inconfidência. Depois de muito papo, o Plínio pediu que eu e Paulo fizéssemos croquis de nossos projetos. Fiz o meu e Plínio disse: $2 \circ$ lugar - e Paulo fez o seu e ele disse: 1은 lugar. Foi emocionante!

O mal-entendido só foi esclarecido na exposição dos projetos. O projeto do Artigas tinha, de fato, tirantes, mas não era sua marca - fizera uma releitura do Museu de Caracas do Niemeyer e muitas outras soluções originais de subsolo, aliás, como a do Paulo e a do meu próprio.

Não sei se foi coincidência ou não, mas o fato é que alguns anos mais tarde, Artigas nos convidou para sermos seus assistentes na FAUUSP, para grande espanto da comunidade acadêmica. Dois arquitetos do Mackenzie para lecionar na FAU não era uma coisa aceitável de pronto. A lição que todos aprenderam é que Artigas não queria "cupinchar", como se dizia, mas pessoas, arquitetos que, antes de tudo, trouxessem exuberância em sua produção e participassem ativamente em todos os espaços que nos permitiam.

Nessa mesma quadra de nossas vidas fiz o Concurso de Brasília com o Julio Neves, Rubens Paiva e Carlos Anders. Artigas e Lucio Costa eram os favoritos. Fato curioso, Artigas no Rio, Lucio em São Paulo.

Como todos sabem, Lucio Costa venceu o conclave e Artigas se classificou em 5o lugar (ex 
aequo com Henrique Mindlin, Giancarlo Palanti, e a Construtécnica - Milton Ghiraldini e Clovis Felipe Olga).

O projeto de Artigas trazia como co-autores os pesos pesados como o doutor Mario Wagner, Paulo Camargo de Almeida e Carlos Cascaldi.

$O$ resultado desse concurso foi muito importante para a arquitetura brasileira. O projeto do Artigas foi logo reconhecido como o mais abrangente no tocante ao desenvolvimento do interior do país, e levava a marca de sua instintiva postura política. Um projeto denso, celebrado pelo júri presidido pelo urbanista inglês sir William Holford como o que mais aprofundou os estudos da região. No dia seguinte, o Correio da Manhã dizia: "Lucio Costa estréia em literatura fazendo urbanismo".

Nesse caleidoscópio de circunstâncias tenho a lembrança e o pesar que nós provocávamos muitas "saias justas" para o Artigas. Ele era quase sempre membro de júri em concursos que Paulo Mendes e eu participávamos. Foi assim no 5a Avenida, no Clube da Orla, Escola Aeronáutica de Pirassununga e Petrobrás Rio.

Voltando a 1962, ano de meu ingresso na FAUUSP como assistente de Artigas, sendo reitor Ulhôa Cintra e diretor o arquiteto Anhaia Mello, fomos convidados para rever o plano da Cidade Universitária Armando de Salles Oliveira, sob coordenação de Paulo Camargo de Oliveira.

O grupo original era composto por Vilanova Artigas, Ícaro de Castro Mello, Oswaldo Bratke, Eduardo Kneese de Mello, Roberto Cerqueira César, Eduardo Corona, Carlos Millan, Paulo Mendes da Rocha, Joaquim Guedes, e eu próprio.

Para mim foi o maior desafio que já enfrentara, no meio de tantos arquitetos experimentados, projetar além da revisão do plano e edifício da Geologia, Petrografia, Paleontologia e Mineralogia. Minha inibição era uma realidade que, por si só, foi rompida com a apresentação do Artigas para o edifício da FAUUSP. Artigas, nesse projeto, exibia com raro brilho toda sua bagagem profissional.

Foi um acontecimento para mim, e, creio, para os demais membros da equipe. Até hoje faço referência em minhas aulas à habilidade com que Artigas trabalhou os aspectos estruturais da edificação. O tromp l'oeil da fachada, a precisão das soluções estruturais, o agenciamento da planta vis-à-vis, a espacialidade única ficará para sempre na história da arquitetura brasileira, por mais que alguns desafetos the neguem a genialidade.

A extraordinária criatividade que Artigas exibia nessa época de sua vida foi dramática e traumaticamente truncada pelo golpe de $1^{\circ}$ de abril. Desses anos de chumbo tenho más lembranças do convívio com Artigas. Suas angústias provocadas por prisões, seu isolamento freqüente, seu exílio no Uruguai só eram compensados por alguns almoços na Cantina Roma, quando o vinho temperava nossas conversas e distraía-lhe o espírito.

Passaram-se alguns anos, e eu, com problemas nem sempre triviais, aceitei o convite de participar da reabertura da UnB da ICA-FAU. Dias depois de minha chegada a Brasília houve a promulgação do Al-5, e, em seguida, a cassação dos colegas Jon A. Vergareche Maitrejean, Paulo Mendes da Rocha e Artigas.

Era uma época parecida com a retratada no filme La guerre est fini. Notícias, boatos e a distância nos separavam por uns tempos. Na volta de Brasília, um ano depois, fui eleito presidente do IAB-SP, na mesma época em que participei do Planejamento Físico do Plano de Desenvolvimento Integrado da Grande Florianópolis e da Ponte Colombo Salles. Nessa ocasião, convidamos Artigas, Jorge Wilheim e Eduardo Kneese de Mello para palestras e discussões sobre o plano de Florianópolis. Artigas se relacionou admiravelmente com o colega Luiz Felipe Gama D’Eça, pessoa extraordinária na história de Florianópolis, e manteve com ele uma rica correspondência, enviando-Ihe, inclusive, um artigo que descobrira em uma de suas viagens a Nova York, do viajante inglês Mawe, a respeito de Florianópolis. Nessa oportunidade, com o grupo que eu trouxe de Brasília para Florianópolis, fundamos o departamento do IAB de Santa Catarina.

Na gestão do prefeito Colassuono, Alberto Botti sucedeu Roberto de Cerqueira César na presidência da Emurb. Nessa ocasião, fui convidado a participar da diretoria como diretor de Planejamento. Nunca havia exercido cargo público, a não ser na USP e na UnB. Engajei-me com entusiasmo na nova atividade, ciente dos problemas de conviver com o regime militar. Cito essas preliminares porque têm a ver com o Artigas. 


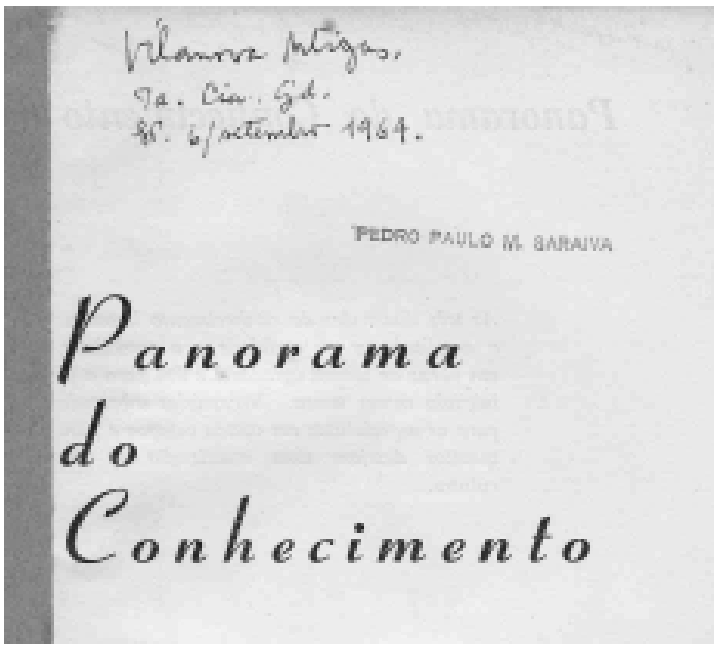

Logo de início recebemos (Emurb) a solicitação de contratar alguns projetos, sendo o mais importante o do Anhangabaú, sua reurbanização e readequação. Convidei-o, não por "nepotismo", mas porque tinha a firme convicção que ele era o arquiteto mais qualificado para a tarefa. A contratação, no bojo de outras três, tinha de ser aprovada pela diretoria, composta por engenheiros, administradores e por um advogado, antigo delegado do DOPS, doutor Ribeirinho. Quando propus o nome de Artigas, ele pediu a palavra e disse: "foi meu preso, mas é um patriota - sou pela contratação..."

O projeto do Anhangabaú, que teve a participação da arquiteta Marlene Yurgel e de Abraão Sanovicz, não foi implementado. Todo seu desenvolvimento foi muito prejudicado pelos infindáveis afastamentos de Artigas pelo regime. Mas essa é uma outra história que não cabe nestas breves lembranças.

Retornei à FAUUSP, mas em 1974 não quis ser recontratado, pois nunca o fora, nomeado, sim, pelo governador Carvalho Pinto, por indicação de
NOTA:

Fac-símile da primeira página do livro Panorama da arquitetura, Coleção Panorama do Conhecimento, que Artigas leu durante a prisão e com o qual depois me presenteou. Arquivo: Arquiteto Pedro Paulo de Melo Saraiva

Artigas, de Anhaia Mello e Ulhôa Cintra, respectivamente, professor titular, diretor da FAU e reitor da USP.

Distanciamo-nos um pouco, mas assisti com todos o renascer do velho mestre, cujo exemplo mais notável é o Terminal Rodoviário de Jaú.

A notícia do falecimento de Artigas me foi dada por Alfredo Paesani, por telefone. A longa luta que travara chegara ao fim. Alguns eventos como submissão e a defesa de sua cadeira na FAU não devem ter ajudado em nada seu tratamento. Fiquei deprimido, impotente para enfrentar a estrada a fim de prestar a merecida homenagem.

Hoje guardo somente os bons e frutíferos momentos que passamos juntos na defesa de nossa cultura e de nossa pátria.

P.S.: Não entendo porque uma universidade que tem um dos maiores monumentos da cidade dedicado ao engenheiro Ramos de Azevedo não haja, ainda, erigido um cenotáfio à altura da importância de um arquiteto o qual, a cada dia, mostra-se mais atual.

\section{Pedro Paulo Saraiva}

Ex-professor do Departamento de Projeto da FAUUSP, atualmente é professor da Faculdade de Arquitetura da Universidade Mackenzie e Anhembi Morumbi. 